\title{
Téoros
}

Revue de recherche en tourisme

\section{La pollution du fleuve : état d'urgence}

\section{Ginette Lachance}

Volume 6, numéro 2, juillet 1987

Le Saint-Laurent magnétique

URI : https://id.erudit.org/iderudit/1080503ar

DOI : https://doi.org/10.7202/1080503ar

Aller au sommaire du numéro

\section{Éditeur(s)}

Université du Québec à Montréal

\section{ISSN}

0712-8657 (imprimé)

1923-2705 (numérique)

Découvrir la revue

\section{Citer cet article}

Lachance, G. (1987). La pollution du fleuve : état d'urgence. Téoros, 6(2), 9-9. https://doi.org/10.7202/1080503ar d'utilisation que vous pouvez consulter en ligne.

https://apropos.erudit.org/fr/usagers/politique-dutilisation/ 


\section{La pollution du fleuve: état $d$ 'urgence}

par Ginette Lachance*

Trait d'union entre les Grands Lacs et l'Atlantique, le Saint-Laurent représente un atout économique et touristique que des générations de Québécois ont pu utiliser à loisir. Il semble aussi qu'ils en aient abusé... Par la pollution, les remblayages inconsidérés et la destruction de sa valeur esthétique, les Québécois continueroni-ils à dilapider cette richesse? Un redressement de la situation s'impose et des mesures commencent d'ailleurs à être prises pour protéger et conserver la qualité de ce milieu.

Au milieu des années 1970, un Comite d'étude fédéral-provincial sur le SaintLaurent ne dénombrait pas moins de 65 plages le long du fleuve, près de 100 terrains de camping et autant dé ports de plaisance. Près de $50 \%$ de ces equipements étaient localisés dans la région située à l'ouest de Montréal. Dans la région de Québec jusqu'à Montmagny, on ne relevait cependant qu'une dizaine de plages et 17 terrains de camping. La situation ne s'est guère améliorée depuis, sauf en ce qui concerne les ports de plaisance qui ont connu un développement sans précédent.

En effet, le fleuve avec ses paysages grandioses, ses centres urbains à caractère historique et culturel, mais aussi avec ses marées et ses forts courants qui constituent en soi un défi pour les navigateurs, présente un attrait grandissant pour les touristes nautiques. L'impulsion donnée par l'événement de la voile Québec '84 et la construction de nouvelles marinas tout le long du Saint-Laurent permettent d'attirer maintenant des visiteurs du bassin des Grands Lacs et de la côte américaine par les voies d'eau de I'Hudson et du lac Champlain.

Liée aux activités nautiques, la villégiature s'est fortement développée entre $1940 \mathrm{et}$ 1970. Toutefois, la dégradation de la qualité de l'eau du fleuve a certes fait plafonner le développement de la villégiature depuis les vingt demières années. L'attrait

\footnotetext{
-Madame Ginette Lachance est geographe au service de la Conservation et Protection, Environnement Canada.
}

des paysages, dans une région comme celle de Charlevoix par exemple, le charme des vieux villages, la facilité d'accès des lacs à l'ouest de Montréal ont par contre maintenu certaines activités de villégiature.

\section{Les détériorations}

De 1972 à 1978, le Comité d'étude sur le fleuve Saint-Laurent a identifie plusieurs problèmes affectant la qualité du SaintLaurent et pouvant limiter les usages qu'on en fait. Le Comité soulignait dans son rapport final la détérioration de la qualité de l"eau due à la dissémination des substan= ces toxiques et à la contamination bactériologique. Le comité notait aussi la dégradation des rives, l'empiètement sur les territoires servant d'habitat à la flore et à la faune, et notamment "la destruction de la valeur esthétique du fleuve, caractérisée par la réduction de la transparence de l'eau, l'encombrement des berges, la présence de nappes d'huile et la prolifération d'algues... (I).

Ces détériorations ont un un effet limitatif sur le développement du potentiel touristique et récréatif du fleuve. La baignade est limitée à quelques rares endroits. Les activités de péche sont déclinantes; en effet, les herbiers accueillants pour la faune du fleuve et les especes de poissons les plus recherchées sont en régression pour faire place à des espèces moins désirables. Les substances toxiques s'accumulent dans la chair de ces poissons et la consommation de ces derniers doit être restreinte.

Les causes de ces détériorations sont multiples: que l'on songe au déversement des eaux usees des municipalités riveraines, aux rejets industriels, a l'usage de pesticides et d'herbicides en milieu agricole, au remblayage des zones littorales, on a un bon aperçu des principales sources de dégradation.

\section{Une volonté de conservation}

Les Québécois ont toutefois entrepris de mettre un terme à la destruction progressive de cette ressource. Un vaste programme d'assainissement des eaux, visant

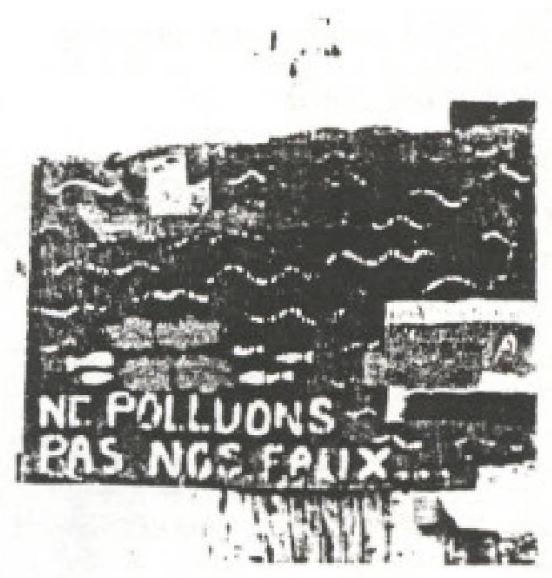

a la fois les secteurs municipal, industriel et agricole, a êté entrepris et des centaines de millions de dollars sont investis chaque année pour la mise en place de systèmes de collecte et de traitement des eaux usées. Les citoyens sont de plus en plus vigilants pour exiger des gouvernements l'évaluation approfondie des impacts de tout projet susceptible d'affecter le fleuve et ses rives. Des groupes $s$ 'activent afin d'acquérir et de conserver les habitats fauniques de grande valeur.

Car il ne s'agit plus seulement de mettre fin aux abus, mais aussi de recouvrer des usages perdus. Si le saumon remonte maintenant la Tamise, peut-être les Québécois des années 1990 pourront-ils à nouveau se tremper l'orteil dans l'eau du fleuve sans craindre pour leur santé.

Le fleuve constitue une richesse qu'il est essentiel de protéger et conserver. Tous, tant les gouvernements, les milieux d'affaires, les groupes que les individus, doivent s'associer à cette tầche gigantesque $f$

\footnotetext{
Rattirance

(1) Comitế d'étude sur le flouve Saint-Laurent. Pour un fleuve de qualité, Supplement du magazine Qubbec-Science, volume 17 , numero 3 , novembre
} 1978. 